DEMOGRAPHIC RESEARCH

VOLUME 37, ARTICLE 59, PAGES 1891-1916

PUBLISHED 13 DECEMBER 2017

http://www.demographic-research.org/Volumes/Vol37/59/

DOI: 10.4054/DemRes.2017.37.59

Research Article

Household structure vs. composition:

Understanding gendered effects on educational progress in rural South Africa

Sangeetha Madhavan

Tyler W. Myroniuk

Randall Kuhn

Mark A. Collinson

(C) 2017 Madhavan, Myroniuk, Kuhn \& Collinson.

This open-access work is published under the terms of the Creative Commons Attribution 3.0 Germany (CC BY 3.0 DE), which permits use, reproduction, and distribution in any medium, provided the original author(s) and source are given credit.

See https://creativecommons.org/licenses/by/3.0/de/legalcode. 


\section{Contents}

$1 \quad$ Introduction $\quad 1892$

1.1 Living arrangements and gender differences in outcomes 1893

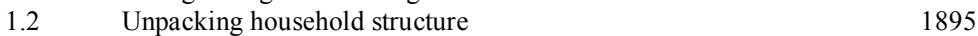

$2 \quad$ Site, data, and methods $\quad 1897$

$\begin{array}{llr}2.1 & \text { Site description } & 1897\end{array}$

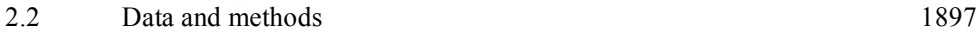

$3 \quad$ Results $\quad 1900$

3.1 Who do children live with in Agincourt? 1900

3.2 Does structure matter for gendered educational outcomes? 1902

$3.3 \quad$ Do kin matter? 1903

$3.4 \quad$ When do kin matter? 1905

$4 \quad$ Discussion and conclusion $\quad 1907$

$\begin{array}{ll}5 & 1909\end{array}$

$\begin{array}{lr}\text { References } & 1910\end{array}$ 


\title{
Household structure vs. composition: Understanding gendered effects on educational progress in rural South Africa
}

\author{
Sangeetha Madhavan ${ }^{1}$ \\ Tyler W. Myroniuk ${ }^{2}$ \\ Randall Kuhn ${ }^{3}$ \\ Mark A. Collinson ${ }^{4}$
}

\begin{abstract}
BACKGROUND

Demographers have long been interested in the relationship between living arrangements and gendered outcomes for children in sub-Saharan Africa. Most research conflates household structure with composition and has revealed little about the pathways that link these components to gendered outcomes.
\end{abstract}

\section{OBJECTIVES}

We offer a conceptual approach that differentiates structure from composition with a focus on gendered processes that operate in the household in rural South Africa.

\section{METHODS}

We use data from the 2002 round of the Agincourt Health and Socio-Demographic Surveillance System. Our analytical sample includes 22,997 children aged 6-18 who were neither parents themselves nor lived with a partner or partner's family. We employ ordinary least squares regression models to examine the effects of structure and composition on educational progress of girls and boys.

\section{RESULTS}

Non-nuclear structures are associated with similar negative effects for both boys and girls compared to children growing up in nuclear households. However, the presence of

\footnotetext{
${ }^{1}$ University of Maryland, College Park, USA. E-Mail: smadhava@umd.edu.

${ }^{2}$ George Mason University, Fairfax, USA.

${ }^{3}$ University of California, Los Angeles, USA.

${ }^{4}$ MRC/Wits University Rural Public Health and Health Transitions Research Unit (Agincourt), School of Public Health, Faculty of Health Sciences, University of the Witwatersrand, South Africa; South African Population Research Infrastructure Network (SAPRIN), Department of Science and Technology/Medical Research Council, South Africa; INDEPTH Network, Ghana.
} 
other kin in the absence of one or both parents results in gendered effects favouring boys.

\section{CONCLUSION}

The absence of any gendered effects when using a household structure typology suggests that secular changes to attitudes about gender equity trump any specific gendered processes stemming from particular configurations. On the other hand, gendered effects that appear when one or both parents are absent show that traditional gender norms and/or resource constraints continue to favour boys.

\section{CONTRIBUTION}

We have shown the value of unpacking household structure to better understand how gender norms and gendered resource allocations are linked to an important outcome for children in sub-Saharan Africa.

\section{Introduction}

Demographers have long been interested in the relationship between living arrangements and children's well-being in sub-Saharan Africa. The people with whom children reside are conduits of physical and social capital and, therefore, key factors influencing their well-being. For starters, parental presence, particularly mothers', has been critically linked to outcomes such as educational attainment (Lloyd and Blanc 1996; Townsend et al. 2002). Extended kin have also long been recognized as critical players in the lives of children (Desai 1992; Lloyd and Desai 1992; Sear et al. 2002), though studies that have examined the effects of extended family arrangements on wellbeing have arrived at inconsistent findings (Buchmann 2000; Doan and Bisharat 1990; Gage, Sommerfelt, and Piani 1996). More recently, a number of studies have focused on the presence of specific kin such as grandparents, finding that grandmothers have a positive influence on educational outcomes (Parker and Short 2009) and birthweight (Cunningham et al. 2010). Recent studies of societies affected by HIV/AIDS have postulated the importance of kin in the care of children (Ankrah 1993; Bicego, Rutstein, and Johnson 2003; Goldberg and Short 2012; Hill, Hosegood, and Newell 2008; Hosegood et al. 2007).

Much of this work conflates household structure and kin presence in examining effects on child outcomes when, in fact, these are different concepts. Kin presence pertains to the availability of specific individuals whereas family structure has to do with the generational configuration and extent of nucleation. Moreover, the effects of kin presence may be moderated by parental presence. Furthermore, we have not paid adequate attention to the ways in which structure and kin presence reflect gender norms 
and resource allocation and are sensitive to economic exigencies. We address both issues in this paper by (1) offering a conceptual approach that explicitly differentiates structure from kin presence and identifies possible pathways that link structure and kin presence to gendered outcomes and (2) demonstrating the value of such an approach by focusing on the educational progress for boys and girls in a rural context in South Africa - a setting particularly well suited for this analysis for two reasons. First, as a result of apartheid-era policies, high levels of unemployment, and cultural preference, Black family organization defies simplistic, conventional categorization including gender roles. Second, Black African ${ }^{5}$ children in rural South Africa continue to face large disadvantages in educational attainment compared to other racial groups. These inequalities underscore the need to better understand which aspects of household arrangements matter for educational outcomes and the extent of persistent gender differences.

\subsection{Living arrangements and gender differences in outcomes}

A number of scholars have examined differential effects of living arrangements on outcomes for boys and girls in Africa. Educational outcomes, in particular, have received notable attention. Lloyd and Blanc, in their oft-cited cross-national study using Demographic and Health Surveys (DHS) data from seven sub-Saharan African countries, claimed that they found "no evidence that family support systems operate systematically to the benefit of boys relative to girls" (Lloyd and Blanc 1996: 267). In the two decades since, researchers have tested this claim using different measures of household composition and have arrived at equivocal findings. Driven in large part by the HIV/AIDS epidemic, living without biological parents - maternal, paternal, or double orphanhood - has often been employed as an indicator of children's vulnerability. Reports by the World Bank (2002) and UNAIDS (2002) suggested that orphaned girls face disadvantages in school enrollment compared to orphaned boys. Similar to Lloyd and Blanc (1996), Case, Paxson, and Ableidinger (2004: 500) although they analyzed more countries and DHS waves - found that the effect of orphanhood on the chances of school enrollment are "equally severe" for boys and girls. Subsequent analyses found a more nuanced relationship, however. For instance, in Uganda, orphaned girls are less likely to receive any secondary schooling and are slower at progressing through the educational system than girls who were not orphaned, whereas there are no differences in educational attainment by orphan status among boys (Yamano, Shimamura, and Sserunkuuma 2006). But in a study based in rural Kenya,

${ }^{5}$ We retain the term "Black African" to be consistent with current-day usage in both academic and policy arenas. 
girls and boys, on average, do not significantly differ in terms of school participation following a parent's death; however, when considering age, young girls are more likely than any other group to attend school less frequently if orphaned (Evans and Miguel 2007).

Headship and presence of siblings have also been used to examine gendered differences in educational achievement. Young girls in Kinshasa were found to have lower levels of education if they lived in a household headed by a woman while older boys enjoy educational advantages (Shapiro and Tambashe 2001). However, orphaned girls in female-headed households in rural Zimbabwe actually have better chances of completing primary school compared to boys and nonorphaned girls (Nyamukapa and Gregson 2005). Girls living with mothers with some education and older sisters appear to enjoy some educational advantages in Nigeria (Kazeem, Jensen, and Stokes 2010) likely due to the presence of female role models. The presence of a male pensioner, a critical source of financial support, has also been linked to higher educational achievement for girls but not for boys (Hamoudi and Thomas 2005). At the same time, girls in very large households (Mabika and Shapiro 2012), or in households with many young children (Lindskog 2013), have lower educational achievement and school attendance than boys, possibly due to resource constraints and son preference. Finally, work done in rural South Africa suggests even greater nuance when unpacking the effects of household composition on education. Townsend et al. (2002) found that boys' and girls' educational attainment is differentially influenced by factors such as female headship, multigenerational household, and the presence of both parents.

Other outcomes such as nutritional status, the onset of sexual activity and early childbearing, and labour force entry are also related to household composition and have a gendered dimension. For example, a girl living with a female pensioner in South Africa has a higher chance of overcoming nutritional deficits, but no such effect is evident for boys (Duflo 2000). The presence of a father is linked to a delay in sexual debut for girls, but not boys, in Ivorian households (Babalola, Tambashe, and Vondrasek 2005). It is possible that social control and vigilance by fathers discourages early sexual activity for daughters, which also lowers the risk of unwanted pregnancies (Ngom, Magadi, and Owuor 2003). Finally, recent work has focused on family dynamism and found that family instability - measured through marital dissolutions has mixed gendered benefits. Whereas it has no notable gendered effects on the timing of sexual debut in western Kenya (Goldberg 2013a), family instability was associated with differential effects by gender on multiple outcomes in urban South Africa (Goldberg 2013b). 


\subsection{Unpacking household structure}

Our approach builds on the extant research by unpacking how household structure, as it is used in the literature, conflates two dimensions: structure and composition. Structure, as we use it, refers to the generational contours and the extent of nucleation in the household. Nuclear arrangements, i.e., only parents and children, are often identified with lower fertility and changing values about family obligations (Bongaarts 2001; Mberu 2007). The shift from quantity to quality, accompanied by parents' increasing educational attainment, should result in more gender-egalitarian values about the treatment of boys and girls, even if this process is a consequence of intra-household gendered bargaining about child investments. In other words, women and men with more education will advocate equally for their daughters and sons (Glick and Sahn 2000; Thomas 1990). Exceptions exist, of course; for example, Das Gupta (1987) found that with smaller family size, son preference actually intensifies in northern India.

Conversely, extended households are often seen as having more patriarchal norms that result in gendered outcomes favouring boys. This may, however, be indicative of the lower education and higher fertility that usually characterizes these households (for a review, see Dodoo and Frost 2008). Large extended households also expose fault lines in the household, particularly along gender (Folbre 1986; Sen 1990) and age (Meillasoux 1981). Resources are not equitably distributed amongst household members with some members - elder males - benefiting more than others. It would also mean that decision-making power about resource allocation is concentrated amongst elder males who may, in turn, favour investment in boys. Within extended households, however, there is likely to be variation in the extent to which gender inequity is practiced. For example, contiguous vertical arrangements, e.g., grandparents, parents, children, may be more likely to favour boys over girls because they are more likely to be headed by an older male (Stucki 1995). However, such arrangements may be economically more stable, which might result in more equitable treatment of boys and girls. Moreover, the increasing value of older persons as active participants in income generation through pensions (Case and Deaton 1998) may further alter gender-based decision making. Skipped-generation arrangements in which parents are absent often go along with considerable financial and caregiving pressures on the household, which could either reinforce or relax conservative gender norms favouring boys. Laterally extended households that include adult siblings of parents might be more inclined to be gender-neutral because of the absence of elders, but competition for limited resources may work against girls. Structures that encompass both vertical and lateral features may be selective in the application of gendered norms. For example, members may accord equal treatment to boys and girls on health-related issues but may resort to genderbased practices for decisions around education. Finally, structures without vertical or lateral adult kin, i.e., lone-mother households, while free of patriarchy or gerontocratic 
control, do not offer the safety net in terms of financial and practical support found in multigenerational households (Casper and Bianchi 2002; Haider and McGarry 2006), even though even amongst this group variation has been noted along class, education, and racial/ethnic lines (Brady and Burroway 2012; Edin and Lein 1997).

Composition, as we see it, is about the individuals who comprise the structure, namely, parents, siblings, grandparents, aunts, uncles, and other kin. The focus on parental presence in the lives of children in both developed and developing country contexts (Lloyd and Blanc 1996; Townsend et al. 2002) reflects an increasingly dominant view that parents do (and should) shoulder the lion's share of caregiving responsibilities and have primary decision-making power for their children. Cultural norms that promote a socially dispersed childrearing model, through practices such as fosterage (Bledsoe and Isiugo-Abanihe 1985; Isiugo-Abanihe 1985), emphasize the important roles of grandparents (Cunningham et al. 2010; Parker and Short 2009), male kin who take on "social father" roles (Mkhize 2006; Richardson 2009), and female kin who take on "social mother" roles (Madhavan et al. 2012) as sources of financial support, nurturing, and discipline. These adults assume responsibility and have some say in decision-making. Older siblings are often critical sources of role modelling (Madhavan and Crowell 2014). Each of these people, therefore, brings different constraints and opportunities to his/her relationship with the child, which, in turn, may condition the type of influence each person has. We suggest that these dyadic processes are likely to have effects on educational progress that are different from those emanating from a nuclear or extended family arrangement. These effects may come through underlying power dynamics and decision-making power that, taken together, determine investment (financial and mentoring) in girls' and boys' education.

In this paper, we address the following three questions:

1) Does type of household structure influence boys' and girls' schooling differently?

2) Does the presence of particular kin influence boys' and girls' schooling differently net of parental status?

3) Does the effect of kin on schooling depend on parental status, and do the effects vary by sex of child? 


\section{Site, data, and methods}

\subsection{Site description}

The Agincourt subdistrict in Mpumalanga Province in northeastern South Africa is typical of much of southern Africa in three important respects: (1) The land is insufficiently fertile to support the population through subsistence agriculture or other local activities, (2) there are very few local employment opportunities, and (3) the population has high levels of migration and mobility. Formerly part of the apartheid-era homeland system, the area encompasses a population of about 90,000 dispersed in 28 villages established through forced resettlement between 1920 and 1970. All villages have water provided through neighborhood taps, and most have electricity. Villages also have at least one primary school, and most have a secondary school nearby. The main languages spoken in the area are Shangaan and sePedi. Traditionally, most families have lived in multigenerational, extended family arrangements in which adult siblings live close to one another (Junod 1962; Niehaus 2001), although these patterns are undergoing change as a result of increased female migration and alteration in the labour market.

In examining the influence of living arrangements on educational outcomes, previous work using data from 1997 found that the presence of parents benefited educational attainment for all children, but having a migrant father (compared to having a nonmigrant father) had a positive effect only for older children, and female headship had no effect (Townsend et al. 2002). More recent analyses examining the correlates of children's mobility found that the presence of women who can act as maternal substitutes lowers the likelihood of children moving when the mother is a labour migrant or when she is deceased (Madhavan et al. 2012). While providing important findings, these studies have measured extended living arrangements based only on headship, age-sex composition of the household, and generational structure, making it difficult to identify the critical dimensions and the pathways through which effects are felt.

\subsection{Data and methods}

The data for this analysis comes from the Agincourt Health and Socio-Demographic Surveillance System (HDSS) conducted in 21 villages. The baseline census was conducted in 1992, followed by annual visits to each household in the site to update births, deaths, and migration and individual status such as residence, union, relationship to household head, and education of every household member. Migration has been 
classified into two categories. A 'permanent' migrant is defined as a person moving into or out of a household with a permanent intention. Someone who left the household permanently since the last update will not appear on the subsequent household roster. A 'temporary' migrant, on the other hand, is someone who is identified as a member of the household but has spent six or more months of the previous year out of the household for employment or other reasons. This categorization results in a much more expansive definition of coresidence than that which is normally used in censuses and surveys because members who are not physically present are still counted as coresidents if they are temporary migrants.

Collection of data using household rosters almost always begins with the identification of the household head, who tends to be the oldest male (Posel 2001). All other household members are assigned a relationship code in reference to the head. If we wanted to identify relationships from the perspective of children, we would need to transform the relationships that are based on household head. While doing this is relatively straightforward in nuclear and small households, it becomes increasingly difficult in large households extended along both vertical and lateral dimensions. An untapped aspect of the Agincourt data enables us to determine linkages of children to specific coresident and nonresident kin. Our data comes from two sources: (1) household rosters that collect conventional data on sex, age, and relationship to household head and (2) the innovative social connections database (SCDB) that uses multiple waves of the HDSS to derive robust indicators of both intra- and interhousehold connectivity from the child's perspective. Nonresidential kinship links to children were identified through retrospectively tracking local mobility within the DSS site

We use data from the 2002 Agincourt HDSS update that covers a population of approximately 70,000 people living in 11,900 households. Even though it is dated, the 2002 round is well suited for demonstrating the value of our conceptual framework because it offers high-quality data on kin relationships and provides a robust baseline for future work that will examine change over time. Our analytical sample includes 22,997 children aged 6-18 who were neither parents themselves nor lived with a partner or partner's family. The last restriction was imposed to avoid combining caregiving received by children and caregiving given to children in the case of young parents, both of which are very different contexts. ${ }^{6}$ For each child we constructed an egocentric list relating all coresident adult household members (known as alters) to the child (ego). This produced a total of 87,199 adult coresident alters and a mean of 3.79 alters per child. We include only alters age 19+ because they are most critical for channeling

\footnotetext{
${ }^{6}$ As a more robust approach to excluding teen parents, we instead restricted the sample to children age $6-15$ to focus on children who were before childbearing age. For both males and females, all coefficients were of the same sign and significance level as in the 6-18-year-old models.
} 
resources to children. However, because children are an indicator for the competition over resources, our regression models control for total number of children under age 18 living in the household. We then used the SCDB to confirm $96.2 \%$ of the relationships of coresident alters to the child with high confidence. To create the structural typology, we relied on age and relationship. For the kin presence models we aggregated counts of coresident alters according to kinship type (grandparent, aunt, uncle, etc.) and created dichotomous indicators for the presence of any kin of that type. The data was then collapsed into a single observation for each child.

We employ ordinary least squares (OLS) regression models to examine the relationship between children's living arrangements as specified in each of the approaches and educational outcome. The model sequencing we present is in line with each of the three questions stated earlier and uses both additive and interaction models. Our outcome is children's pace of education. This is a continuous variable that captures the difference between age and years of schooling attained and standardizes it by adding a constant for normal age of entry into school, which is 6 in this community (Kuhn 2006). A pace of 0 indicates that the child is meeting grade-for-age expectations. A pace less than 0 signals that the child is falling behind, and a pace greater than 0 suggests that the child is moving faster than expected.

Although our analyses are cross-sectional and cannot empirically identify causal relationships, we minimize the inherent bias by accounting for the most relevant, and observed, other predictors of educational attainment in rural South Africa. Thus, we control for age of child, educational attainment of the household head (which proxies for household socioeconomic status [SES]), whether the house is headed by a refugee, whether there are labour migrants in the household, the number of children under the age of 19 in the household (not including focal child), and the number of adults in the household. While we acknowledge that there are different ways to measure household SES, most notably a wealth index (Spaull 2013; Taylor and Yu 2009), we opted for the educational attainment of the household head, which has been used in previous work (Lam, Ardington, and Leibbrandt 2011; Townsend et al. 2002) because it offers a morefocused dimension of SES directly relevant to our outcome of interest in this context. We first ran sex-pooled models with an interaction term. If the interaction term was significant, we proceeded to sex-stratified models. To control for correlated standard errors arising from having multiple children from the same household, we employ the cluster command in Stata at the household level. 


\section{Results}

\subsection{Who do children live with in Agincourt?}

We begin by exploring the unique coresidence conditions of the Agincourt area. Figure 1 shows the distribution of children living with mothers, fathers, siblings, and different types of extended kin in 2002. Each relationship type is derived from eight elemental codes noted below the graph. We only include the most common living arrangements found in the area. These categories are not mutually exclusive but rather provide an overview of living arrangements.

Figure 1: Proportion of children coresiding with parents, siblings, and extended kin for children aged 6-18, Agincourt 2002

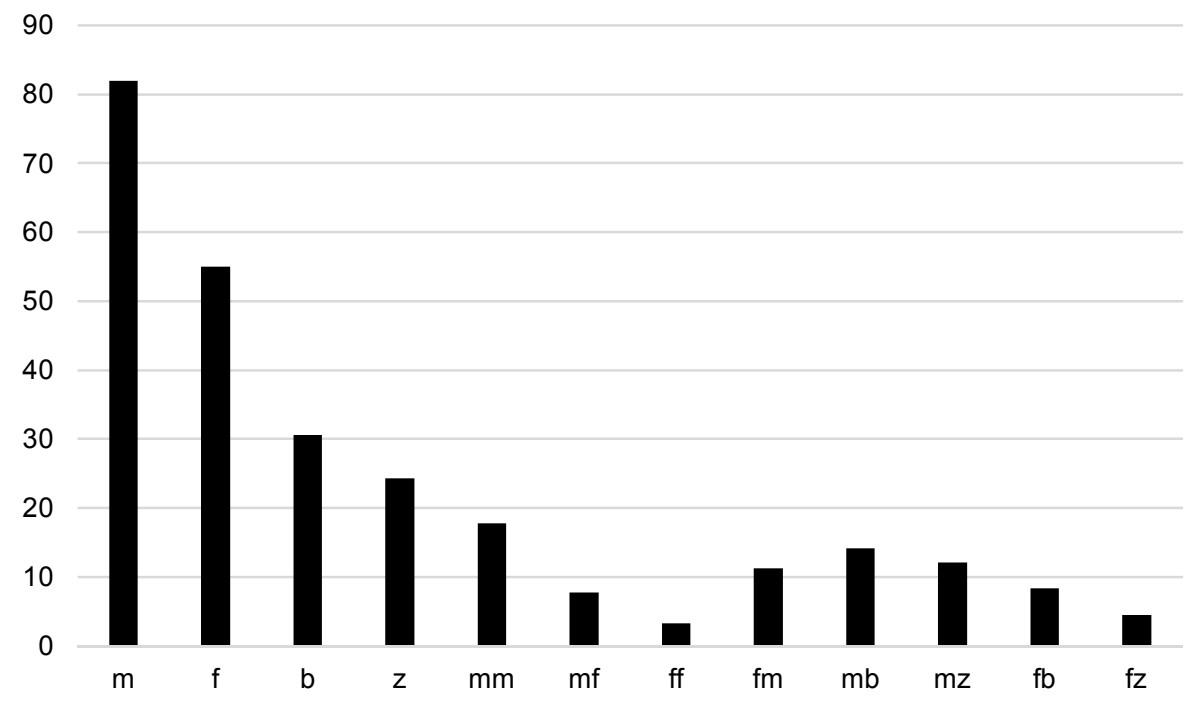

Note: Kinship relationship codes are derived from the eight elemental relationships: mother $(\mathrm{m})$, father $(\mathrm{f})$, brother $(\mathrm{b})$, sister $(\mathrm{z})$, son $(s)$, daughter $(d)$, husband $(h)$, and wife $(w)$. These are combined to represent mother's mother $(\mathrm{mm})$, mother's father $(\mathrm{mf})$, father's father (ff), father's mother ( $\mathrm{fm}$ ), mother's brother $(\mathrm{mb})$, mother's sister ( $\mathrm{mz})$, father's brother (fb), and father's sister (fz). Uncommon relationships such as mother's husband (stepfather) are not included.

Consistent with expectations, we find that most children (82\%) live with their mothers and about $55 \%$ with their fathers. While not shown, just over $50 \%$ of boys and girls live with both parents, which challenges the popular 'absent father' trope. These high proportions are partly attributable to the inclusion of temporary migrants as household members described in the data section. However, it should be noted that 
about $14 \%$ of girls and boys live with neither parent. Moreover, $30 \%$ live with a brother, and $25 \%$ live with a sister (independent of parental coresidence). Interestingly, while half of the children live with some kind of extended kin, less than $20 \%$ live with any particular type of maternal extended kin - grandmothers ( $\mathrm{mm})$, uncles $(\mathrm{mb})$, and aunts (mz) - and less than $10 \%$ live with paternal extended kin ( $\mathrm{fm}$ or $\mathrm{fb}$ ). There are no significant gender differences in these patterns.

Table 1 presents sex-pooled and sex-stratified distributions of our key independent family structure and kin presence variables in addition to the dependent variable, educational pace.

Table 1: Descriptive statistics of dependent and key independent variables

\begin{tabular}{lrrr}
\hline & Full sample & \multicolumn{1}{c}{ Boys } & Girls \\
\hline Pace of education & $-0.5(1.9)$ & $-0.7(2.0)$ & $-0.3(1.8)$ \\
Structural types & & & \\
$\quad$ Exclusively nuclear (both parents) & $38.8 \%$ & $38.7 \%$ & $38.8 \%$ \\
$\quad$ Exclusively continuous vertical (both or one parent) & $7.5 \%$ & $7.5 \%$ & $7.5 \%$ \\
$\quad$ Exclusively lateral (both or one parent) & $6.2 \%$ & $6.2 \%$ & $6.2 \%$ \\
$\quad$ Lateral and vertical (both or one parent) & $13.1 \%$ & $13.1 \%$ & $13.2 \%$ \\
$\quad$ No parent but any kin present & $11.6 \%$ & $11.5 \%$ & $11.7 \%$ \\
$\quad$ Lone mother & $14.5 \%$ & $14.7 \%$ & $14.3 \%$ \\
$\quad$ Other & $8.3 \%$ & $8.3 \%$ & $8.3 \%$ \\
Parental status & & & \\
$\quad$ Both parents & $51.3 \%$ & $51.4 \%$ & $51.2 \%$ \\
$\quad$ One parent & $33.9 \%$ & $34.0 \%$ & $33.8 \%$ \\
$\quad$ No parents & $14.8 \%$ & $14.6 \%$ & $14.9 \%$ \\
Kin presence & & & \\
$\quad$ Any grandparent & $29.7 \%$ & $29.7 \%$ & $29.7 \%$ \\
Any other kin & $23.0 \%$ & $23.5 \%$ & $22.6 \%$ \\
$\quad$ Any sibling 19+ & $40.6 \%$ & $41.1 \%$ & $40.0 \%$ \\
\hline $\mathrm{N}$ & 22,997 & 11,674 & 11,323 \\
\hline
\end{tabular}

Note: Standard deviations in parentheses.

The mean pace of education for the whole sample is -0.5 , and -0.7 and -0.3 for boys and girls respectively, suggesting that boys are doing worse than girls. In terms of structure, slightly under $40 \%$ of children live in nuclear structures, and approximately $27 \%$ in some variant of extended structures. About $14.5 \%$ live in a lone-mother arrangement, and another $11.6 \%$ live with only kin and no parents. Just over half of all children live with both parents, while $34 \%$ live with one parent - most likely the mother. Moving to type of kin present (not mutually exclusive), about one-third of the sample lives with a grandparent, a quarter with any other kin, and just over $40 \%$ with a sibling older than 19 . There are no notable sex differences. 


\subsection{Does structure matter for gendered educational outcomes?}

Table 2 shows the results of regressions using a structural typology based on the literature and what we know from fieldwork at the site. This typology is an attempt to develop a parsimonious, mutually exclusive categorization that is meaningful and analytically useful. The seven categories are (1) 'exclusively nuclear' (having only both parents and no other kin); (2) 'exclusively continuous vertical' (one or both parents, grandparents); (3) exclusively lateral (one or both parents, aunts, uncles); (4) 'vertical and lateral' (one or both parents and having at least one member from vertical and lateral arrangements); (5) 'no parents but any kin present'; (6) 'lone mother' (no kin); and (7) 'other.' The residual category 'other' includes 'lone father,' 'only adult siblings and/or spouses,' 'only adults with unknown relationships,' 'no adults,' and 'other rare combinations.' Generational divisions are determined by age and relationship.

Table 2: $\quad$ OLS regression results for effects of structural typology on pace of education for children aged 6-18, Agincourt 2002

\begin{tabular}{|c|c|c|}
\hline & Coefficient & SE \\
\hline \multicolumn{3}{|l|}{ Structural type } \\
\hline Exclusively nuclear & Ref. & \\
\hline Exclusively continuous vertical & 0.040 & $(0.07)$ \\
\hline Exclusively lateral & $-0.179^{\star}$ & $(0.08)$ \\
\hline Vertical and lateral & $-0.184^{\star \star *}$ & $(0.05)$ \\
\hline No parent but any kin present & $-0.198^{\star * \star}$ & $(0.05)$ \\
\hline Lone mother & $-0.248^{* * *}$ & $(0.07)$ \\
\hline Other & $-0.239^{* *}$ & $(0.07)$ \\
\hline Structural type $\times$ sex of child & NS & \\
\hline \multicolumn{3}{|l|}{ Controls } \\
\hline Sex of child (female) & $0.403^{\star \star *}$ & $(0.04)$ \\
\hline Age of child & $-0.266^{* * *}$ & $(0.00)$ \\
\hline \# children $<19$ & $-0.025^{\star \star *}$ & $(0.01)$ \\
\hline$\#$ adults $>19$ & $0.057^{\star \star *}$ & $(0.01)$ \\
\hline \# labour migrants & 0.026 & $(0.02)$ \\
\hline Educational status of head & $0.048^{* * *}$ & $(0.00)$ \\
\hline Refugee-headed & $-0.271^{* * *}$ & (0.03) \\
\hline $\mathrm{R}^{2}$ & .2841 & \\
\hline Observations & 20,780 & \\
\hline
\end{tabular}

Note: ${ }^{*} p<0.05,{ }^{* *} p<0.01,{ }^{* * *} p<0.001$. Robust standard errors estimated (in parentheses). Estimates are clustered by household ID.

Being in an exclusively continuous vertical arrangement is no different from being in a nuclear arrangement for maintaining pace of education. This suggests that multigenerational households in which parents are present provide a similar support structure for educational progress as nuclear households. This may not be particularly 
surprising if we see these arrangements as both normative in this context and having greater social and economic stability, which ensures that children receive needed educational support. All the other arrangements have significant negative effects, suggesting that economic pressures and the absence of role models compromise educational progress.

Even though the independent effect of being female has a highly significant positive effect on pace of education, the interaction effect of child's sex and structure is not significant. This suggests that the positive and negative influences of structure on educational progress work similarly for both boys and girls. The independent effects of the control variables are as expected. Age of child is associated with decreasing pace of education. Total number of adults has an independent positive effect, and total number of children has a negative effect. Educational status of the head has the expected positive impact, whereas being in a refugee-headed household has a negative effect. Interestingly, number of labour migrants is not associated with educational pace. These effects are similar for boys and girls. Taken together, these results suggest that structural variation has little impact on gendered outcomes in education. We now turn to a more focused examination of the individual members who make up the structure.

\subsection{Do kin matter?}

We tested numerous model specifications for various types of kin, including counts and dichotomous indicators of kin presence for specific types of kin, for kin classified as lateral/vertical, and for kin classified as maternal or paternal. Because we found that only grandparents and adult siblings have any association with child schooling, the results presented in Table 3 show the more parsimonious categorization. This categorization is consistent with both the literature and the study context. The models follow an additive process to examine the relationship of kin presence and pace of education net of parental status. Model 1 only includes parental status and no controls for kin to better appreciate the effect of kin. Model 2 includes grandparents, and Model 3 adds all other kin and siblings over the age of 19. 
Table 3: OLS regression results for effects of kin presence on pace of education for children aged 6-18, Agincourt 2002

\begin{tabular}{|c|c|c|c|}
\hline & $\begin{array}{c}\text { Model 1 } \\
\text { No controls for kin }\end{array}$ & $\begin{array}{c}\text { Model 2 } \\
\text { Controls for } \\
\text { grandparents }\end{array}$ & $\begin{array}{c}\text { Model } 3 \\
\text { Controls for all kin } \\
\text { and siblings }\end{array}$ \\
\hline \multicolumn{4}{|l|}{ Kin presence $^{\dagger}$} \\
\hline Any grandparent & & $.129^{\star *}(.04)$ & $.187^{* * *}(.05)$ \\
\hline Any other kin & & & $-.061(.06)$ \\
\hline Any sibling $19+$ & & & $.072(.04)$ \\
\hline \multicolumn{4}{|l|}{ Parental status } \\
\hline Both parents & Ref & Ref & Ref \\
\hline One parent & $-.164^{* * *}(.04)$ & $-.222^{\star * *}(.03)$ & $-.215^{\star \star \star}(.032)$ \\
\hline No parents & $-.323^{* * *}(.06)$ & $-.348^{* \star \star}(.04)$ & $-.291^{* \star *}(.05)$ \\
\hline Kin presence $\times$ sex of child & NS & NS & NS \\
\hline \multicolumn{4}{|l|}{ Controls } \\
\hline Sex of child (female) & $.413^{\star * *}(.03)$ & $.413^{\star \star \star}(.03)$ & $.357^{\star \star \star}(.04)$ \\
\hline Age of child & $-.265^{\star \star *}(.00)$ & $-.263^{\star * \star}(.00)$ & $-.267^{\star * \star}(.00)$ \\
\hline \# children & $-.027^{\star \star \star}(.00)$ & $-.026^{\star \star \star}(.00)$ & $-.026^{* \star \star}(.05)$ \\
\hline \# adults & $.051^{* \star *}(.01)$ & $.043^{\star \star \star}(.00)$ & $.035^{\star \star \star}(.01)$ \\
\hline \# labour migrants & $.021(.02)$ & $.023(.02)$ & $.029(.02)$ \\
\hline Education of head & $.045^{\star \star *}(.00)$ & $.047^{* * *}(.00)$ & $.048^{* * *}(.00)$ \\
\hline Refugee-headed & $-.294^{* \star *}(.03)$ & $-.286^{\star \star \star}(.03)$ & $-.281^{* \star *}(.03)$ \\
\hline $\mathrm{R}^{2}$ & .2848 & .2851 & .2862 \\
\hline Observations & 20,780 & 20,780 & 20,780 \\
\hline
\end{tabular}

Note: ${ }^{*} p<0.05,{ }^{* \star} p<0.01,{ }^{* \star *} p<0.001$. Robust standard errors in parentheses. Estimates clustered by household ID. † We include an additional dummy variable for kin who could not be classified in relation to a child (as a control) in order to more accurately estimate the association between the presence of grandparents, other kin, and siblings 19+ and educational pace (results not presented, $\mathrm{p}>0.05, \mathrm{~N}=1741$ ).

Boys and girls who live with only one parent or neither parent fare worse compared to those who live with both parents, which is consistent with the positive effect of nuclear structures found in Table 2. The presence of grandparents (Model 2), when added to the model, is beneficial perhaps because of added resources through pensions. Interestingly, while the significance and direction of the parental status coefficients do not change, the magnitude increases once we control for grandparents. The presence of older siblings makes no difference, and the presence of other kin may actually be a liability, albeit not showing significance. The independent effect of being female is positive and highly significant, but none of the interaction effects are significant at the .05 level. However, when we ran stratified models (not shown), we found that the presence of adult siblings exerts a significant positive effect for boys only. This may be because resources are limited when older siblings are present and are channeled towards boys. It could also be that role modelling effects are more pronounced for boys. All the control variables behave the same way as in the models with household structure (Table 2). All models control for the total number of adults 
living in the household, which is positively associated with child schooling. Coefficients could therefore be interpreted as indicating the benefit of a particular kin type above and beyond the benefit of just having additional adults. But we note that the significance of kin type coefficients does not change if we drop the control for number of adults.

\subsection{When do kin matter?}

Given the importance of parental status net of the presence of other kin, we next explore the possibility that the significance of extended kin will vary by parental status. Indeed, in line with our conceptual framework, one would expect that any effects of kin presence cannot be fully appreciated without the interaction with parent status.

Confirming the previous results, boys and girls who live with both parents appear to have no added benefit from the presence of other types of kin. However, the story changes in one-parent households, where the presence of grandparents has a significant positive impact for boys but not for girls. Boys also benefit from having older siblings in such circumstances, whereas the advantages for girls are marginal. In households with no parents, grandparents have a strong and positive effect on educational pace for boys and only a weak effect for girls. The effects of adult siblings are not significantly associated with boys' or girls' schooling in no-parent households. As in the earlier models, the presence of aunts and uncles bears no relationship to child schooling progress regardless of parental status. It is noteworthy that the positive effect of total number of adults is only apparent for girls in no-parent households, and the negative effect of number of children under the age of 19 is only apparent for boys in one-parent households and in no-parent households. Taken together, these findings suggest that gender differences play out in times of social and economic stress when resource rationing is necessary. In such cases boys appear to win out. 
Table 4: OLS regression results for effects of kin presence on pace of education, by number of parents for children aged 6-18, Agincourt, 2002

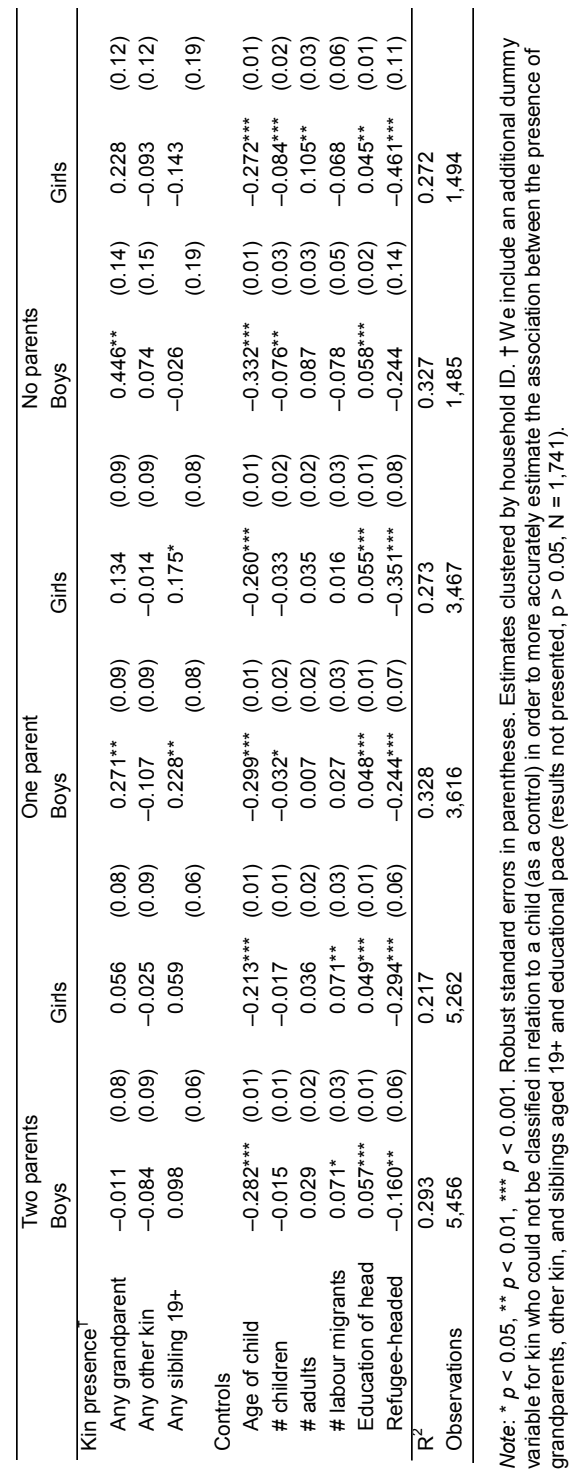




\section{Discussion and conclusion}

Despite the wealth of literature on household structure and children's outcomes in subSaharan Africa, a relatively small number of studies have examined the role of structure and the individuals who comprise that structure in understanding gendered outcomes. In this analysis, we have attempted to push this literature by unpacking how structure is associated with gender norms, decision-making, and allocation of resources, which, taken together, can have a profound influence on outcomes for boys and girls. We used data from a large rural area in South Africa to provide empirical backing for our claims and uncovered a number of interesting findings. To start with, boys fare worse than girls in terms of the pace of education (Table 1). This pattern continues even in a multivariate framework that includes household structure (Table 2) and kin presence (Table 3). However, the more interesting story is with the effects of structure and kin presence on educational attainment. We found that extended kin bear relatively little influence compared to parents on the pace of educational attainment, and this is no different for boys and girls. As shown in the household structure model (Table 2), nuclear structures are the best arrangement for children's education. The kin presence models (Tables 3 and 4) support this finding by showing that the presence of two parents offers a significant benefit for children and is independent of any effects of other kin. In other words, if both parents are there, very little else matters except for the presence of adult siblings, which appears to offer some additional benefit particularly for boys. This is consistent with a recent analysis of South African data showing that children in nuclear arrangements have better educational outcomes compared to those in other arrangements (Pedzisai and Nompumelelo 2016). However, in situations without either parent or even with only one parent, the presence of grandparents and adult siblings benefits boys but not girls. Put simply, if there is a substitution effect in play, it is a gendered one that favours boys.

The most important theoretical contribution of this analysis to the literature on gender and demography is its explicit focus on how household structure and kin presence reflect gender norms and gendered resource allocations in Africa. Most extant literature tends to conflate structure and composition, and none that we are aware of has tried to address the gendered processes that accompanies each. The absence of any gendered effects when using a household structure typology or kin presence suggests that secular changes to attitudes about gender equity trump any specific gendered processes stemming from particular configurations. Moreover, the benefits offered by either a nuclear or exclusively vertical structure underscore the critical role of parents as decision-makers, a point consistent with other works that suggests that the transfer of power from consanguinal to conjugal relationships is underway in Africa (Clark, Kabiru, and Mathur 2010; Smith 2001). Therefore, when parents are present, very little 
else matters. On the other hand, the presence of specific kin in the absence of one or both parents does have gendered effects favouring boys. This reveals two important dimensions: (1) Under conditions of financial and social duress - which is what usually characterizes arrangements without parents - adult caregivers perceive boys to be the better investment, and (2) the absence of parents opens up space for other caregivers to revert to more traditional gender norms favouring boys. Adult siblings, who appear to be as significant as grandparents in their capacity as substitute caregivers or role models, are often neglected in the literature (Kuhn 2006). More puzzling, however, is their influence, which appears to benefit only boys when only one parent - most likely the mother - is present. This suggests that boys more than girls may need more guidance in the form of role modelling when fathers are absent. The role of siblings may be especially important in light of the bimodal pattern of childbearing among Black South African women, in which women often have two children separated by long birth spacing (Garenne, Tollman, and Kahn 2000; Timaeus and Moultrie 2008). In this context, first-born children, particularly boys, may merit special attention not merely because their mothers are often young and lacking spousal support, but because they lack an older sibling.

In assessing the value of this work, it is important to consider some limitations. First, using a cross-sectional indicator of residential arrangements to examine a cumulative process such as schooling tends to result in low explanatory power in general. We cannot, for instance, rule out that the association or lack of association between current extended living arrangements and cumulative schooling outcomes is not a reverse causation. As just one example, children who now live with aunts and uncles may have been previously exposed to a more disadvantaged living arrangement prior to the current one. Therefore, future research should turn to panel data to model the dynamism in arrangements and the timing of such changes. Second, Agincourt HDSS data and the social connections database allow us to measure the effects of noncoresident kin who do not live with a child but may nonetheless play a critical role in providing material support. Recent studies have questioned the limitations of the household as an organizing concept for measuring kinship support (Clark et al. 2017; Madhavan et al. 2017), and so future work ought to address whether kin outside the household increase explanatory power in similar modelling strategies. Third, further refinements of the analysis presented here are possible. For example, it might be informative to cluster on sibling sets within the household to identify more robustly the effect of birth order. Future analyses should investigate interaction effects between age of child and living arrangements on educational progress. Given that we were interested in gendered effects, a complete analysis of this issue was beyond the scope of this paper. However, the very strong negative effect of age in our models provides clear justification to pursue this line of research. Finally, due to data limitations, we did not 
include potentially important covariates such as access to pensions and other social grants, employment status, or temporary migration status.

Despite these limitations, we believe that this analysis makes a worthwhile contribution to ongoing debatesabout the role of family structure in influencing gendered outcomes in the African context. Given the well-documented diversity of family structures in South Africa, it is critical that we not rely on conventional measures of structure that may, at best, give us results that are unclear and, at worst, lead to erroneous conclusions about gendered educational effects. Additionally, disaggregating extended family structures is very important from a policy perspective as it allows a more focused and efficient use of limited resources to target particularly vulnerable children (e.g., girls living without either parent but with a grandparent). We are hopeful that this line of research will be pursued so that findings can be better compared to those stemming from research in high-income contexts, like the United States, where researchers are interested in how the residential presence of fathers and unstable living arrangements might impact boys' and girls' lives (Brown 2010; Hawkins, Amato, and King 2007; Hofferth 2006) and how birth order (Conley 2005) and time spent rearing children (Casper and Bianchi 2002) within stable and unstable family environments predict children's outcomes. Having a global perspective on gender and households would not only enrich theory but present opportunities to develop effective strategies to ensure healthy lives for all children.

\section{Acknowledgements}

We would like to express thanks to key funding partners of the MRC/Wits Rural Public Health and Health Transitions Research Unit who have enabled the ongoing Agincourt Health and Socio-Demographic Surveillance System: the Wellcome Trust, United Kingdom (grants 058893/Z/99/A, 069683/Z/02/Z, and 085477/Z/08/Z); the Medical Research Council, University of the Witwatersrand, and Anglo-American Chairman's Fund, South Africa; the William and Flora Hewlett Foundation (grant 2008-1840), the Andrew W. Mellon Foundation, and the National Institute on Aging (NIA) of the

National Institutes of Health (NIH), United States (grants 1R24AG032112-01 and 5R24AG032112-03). We are grateful for support from the Eunice Shriver National Institutes of Child Health Grant \# R21HD053971. 


\section{References}

Ankrah, E.M. (1993). The impact of HIV/AIDS on the family and other significant relationships: The African clan revisited. AIDS Care 5(1): 5-22. doi:10.1080/ 09540129308258580 .

Babalola, S., Tambashe, B.O., and Vondrasek, C. (2005). Parental factors and sexual risk-taking among young people in Cote d'Ivoire. African Journal of Reproductive Health 9(1): 49-65. doi:10.2307/3583160.

Bicego, G., Rutstein, S., and Johnson, K. (2003). Dimensions of the emerging orphan crisis in sub-Saharan Africa. Social Science and Medicine 56(6): 1235-1247. doi:10.1016/S0277-9536(02)00125-9.

Bledsoe, C.H. and Isiugo-Abanihe, U.C. (1985). Strategies of child fosterage among Mende grannies in Sierra Leone. Presented at the Annual Meeting of the Population Association of America, Boston, March 28-31.

Bongaarts, J. (2001). Household size and composition in the developing world in the 1990s. Population Studies 55(3): 263-279. doi:10.1080/00324720127697.

Brady, D. and Burroway, R. (2012). Targeting, universalism, and single-mother poverty: A multilevel analysis across 18 affluent democracies. Demography 49(2): 719-746. doi:10.1007/s13524-012-0094-z.

Brown, S.L. (2010). Marriage and child well-being: Research and policy perspectives. Journal of Marriage and Family 72(5): 1059-1077. doi:10.1111/j. 1741-3737.2010.00750.x.

Buchmann, C. (2000). Family structure, parental perceptions, and child labor in Kenya: What factors determine who is enrolled in school? Social Forces 78(4): 13491378. doi:10.1093/sf/78.4.1349.

Case, A. and Deaton, A. (1998). Large cash transfers to the elderly in South Africa. The Economic Journal 108: 1338-1361. doi:10.1111/1468-0297.00345.

Case, A., Paxson, C., and Ableidinger, J. (2004). Orphans in Africa: Parental death, poverty, and school enrollment. Demography 41(3): 483-508. doi:10.1353/dem. 2004.0019.

Casper, L. and Bianchi, S. (2002). Change and continuity in the American family. Thousand Oaks: Sage Publications. 
Clark, S., Kabiru, C., and Mathur, R. (2010). Relationship transitions among youth in urban Kenya. Journal of Marriage and Family 72(1): 73-88. doi:10.1111/j. 1741-3737.2009.00684.x.

Clark, S., Madhavan, S., Beguy, D., Kabiru, C., and Cotton, C. (2017). Who helps single mothers in Nairobi? The role of kin support. Journal of Marriage and Family 79(4): 1186-1204. doi:10.1111/jomf.12404.

Conley, D. (2005). The pecking order: A bold new look at how family and society determine who we become. New York: Vintage.

Cunningham, S.A., Elo, I.T., Herbst, K., and Hosegood, V. (2010). Prenatal development in rural South Africa: Relationship between birth weight and access to fathers and grandparents. Population Studies 64(3): 229-246. doi: $10.1080 / 00324728.2010 .510201$.

Das Gupta, M. (1987). Selective discrimination against female children in rural Punjab, India. Population and Development Review 13(1): 77-100. doi:10.2307/1972 121.

Desai, S. (1992). Children at risk: The role of family structure in Latin America and West Africa. Population and Development Review 18(4): 689-717. doi:10.2307/ 1973760.

Doan, R.M. and Bisharat, L. (1990). Female autonomy and child nutritional status: the extended-family residential unit in Amman, Jordan. Social Science and Medicine 31(7): 783-789. doi:10.1016/0277-9536(90)90173-P.

Dodoo, F.N.A. and Frost, A.E. (2008). Gender in African population research: The fertility/reproductive health example. Annual Review of Sociology 34: 431-452. doi:10.1146/annurev.soc.34.040507.134552.

Duflo, E. (2000). Child health and household resources in South Africa: Evidence from the Old Age Pension program. American Economic Review 90(2): 393-398. doi:10.1257/aer.90.2.393.

Edin, K. and Lein, L. (1997). Making ends meet: How single mothers survive welfare and low-wage work. New York: Russell Sage Foundation.

Evans, D.K. and Miguel, E. (2007). Orphans and schooling in Africa: A longitudinal analysis. Demography 44(1): 35-57. doi:10.1353/dem.2007.0002.

Folbre, N. (1986). Cleaning house: New perspectives on households and economic development. Journal of Development Economics 22(1): 5-40. doi:10.1016/ 0304-3878(86)90051-9. 
Gage, A., Sommerfelt, A.E., and Piani, A.L. (1996). Household structure socioeconomic level and child health in sub-Saharan Africa. (Demographic and health surveys analytical report 1) Calverton: Macro International.

Garenne, M., Tollman, S., and Kahn, K. (2000). Premarital fertility in rural South Africa: A challenge to existing population policy. Studies in Family Planning 31(1): 47-54. doi:10.1111/j.1728-4465.2000.00047.x.

Glick, P. and Sahn, D.E. (2000). Schooling of girls and boys in a West African country: The effects of parental education, income, and household structure. Economics of Education Review 19(1): 63-87. doi:10.1016/S0272-7757(99)00029-1.

Goldberg, R.E. (2013a). Family instability and early initiation of sexual activity in Western Kenya. Demography 50(2): 725-750. doi:10.1007/s13524-012-0150-8.

Goldberg, R.E. (2013b). Family instability and pathways to adulthood in Cape Town, South Africa. Population and Development Review 39(2): 231-256. doi:10.1111/j.1728-4457.2013.00590.x.

Goldberg, R.E. and Short, S.E. (2012). 'The luggage that isn't theirs is too heavy...': Understandings of orphan disadvantage in Lesotho. Population Research and Policy Review 31(1): 67-83. doi:10.1007/s11113-011-9223-4.

Haider, S.J. and McGarry, K. (2006). Recent trends in income sharing among the poor. In: Blank, R., Danziger, S., and Schoeni, R.F. (eds.). Working and poor: How economic and policy changes are affecting low wage workers. New York: Russell Sage: 205-232.

Hamoudi, A. and Thomas, D. (2005). Pension income and the well-being of children and grandchildren: New evidence from South Africa. (Working paper: California Center for Population Research).

Hawkins, D.N., Amato, P.R., and King, V. (2007). Nonresident father involvement and adolescent well-being: Father effects or child effects? American Sociological Review 72(6): 990-1010. doi:10.1177/000312240707200607.

Hill, C., Hosegood, V., and Newell, M.L. (2008). Children's care and living arrangements in a high HIV prevalence area in rural South Africa. Vulnerable Children and Youth Studies 3(1): 65-77. doi:10.1080/17450120701602091.

Hofferth, S.L. (2006). Residential father family type and child well-being: Investment versus selection. Demography 43(1): 53-77. doi:10.1353/dem.2006.0006. 
Hosegood, V., Floyd, S., Marston, M., Hill, C., McGrath, N., Isingo, R., Campin, A., and Zaba, B. (2007). The effects of high HIV prevalence on orphanhood and living arrangements of children in Malawi, Tanzania, and South Africa. Population Studies 61(3): 327-336. doi:10.1080/00324720701524292.

Isiugo-Abanihe, U.C. (1985). Child fosterage in West Africa. Population and Development Review 11(1): 53-73. doi:10.2307/1973378.

Junod, H.L. (1962). The life of a South African tribe. New Hyde Park: University Books.

Kazeem, A., Jensen, L., and Stokes, C.S. (2010). School attendance in Nigeria: Understanding the impact and intersection of gender, urban-rural residence, and socioeconomic status. Comparative Education Review 54(2): 295-319. doi:10.1086/652139.

Kuhn, R. (2006). The effects of fathers' and siblings' migration on children's pace of schooling in rural Bangladesh. Asian Population Studies 2(1): 69-92. doi:10.1080/17441730600700572.

Lam, D., Ardington, C., and Leibbrandt, M. (2011). Schooling as a lottery: Racial differences in school advancement in urban South Africa. Journal of Development Economics 95(2): 121-136. doi:10.1016/j.jdeveco.2010.05.005.

Lindskog, A. (2013). The effect of siblings' education on school-entry in the Ethiopian highlands. Economics of Education Review 34: 45-68. doi:10.1016/j.econedu rev.2013.01.012.

Lloyd, C.B. and Blanc, A.K. (1996). Children's schooling in sub-Saharan Africa: The role of fathers, mothers, and others. Population and Development Review 22(2): 265-298. doi:10.2307/2137435.

Lloyd, C.B. and Desai, S. (1992). Children's living arrangements in developing countries. Population Research and Policy Review 11(3): 193-216. doi:10.1007/ BF00124937.

Mabika, C.M. and Shapiro, D. (2012). School enrollment in the Democratic Republic of the Congo: family economic well-being, gender, and place of residence. African Population Studies 26(2): 197-220. doi:10.11564/26-2-213.

Madhavan, S. and Crowell, J. (2014). Who would you like to be like? Family, village, and national role models among Black youth in rural South Africa. Journal of Adolescent Research 29(6): 716-737. doi:10.1177/0743558413502535. 
Madhavan, S., Clark, S., Beguy, D., Kabiru, C., and Gross, M. (2017). Moving beyond the household: Innovations in data collection on kinship. Population Studies 71: 117-132. doi:10.1080/00324728.2016.1262965.

Madhavan, S., Schatz, E., Clark, S., and Collinson, M. (2012). Child mobility, maternal status, and household composition in rural South Africa. Demography 49(2): 699-718. doi:10.1007/s13524-011-0087-3.

Mberu, B. (2007). Household structure and living conditions in Nigeria. Journal of Marriage and the Family 69(2): 513-527. doi:10.1111/j.1741-3737.2007.00 380.x.

Meillasoux, C. (1981). Maidens, meal and money: Capitalism and the domestic community. Cambridge: Cambridge University Press.

Mkhize, N. (2006). African traditions and the social, economic and moral dimensions of fatherhood. In: Richter, L. and Morrell, R. (eds.). Baba: men and fatherhood in South Africa. Pretoria: HSRC Press: 183-198.

Ngom, P., Magadi, M.A., and Owuor, T. (2003). Parental presence and adolescent reproductive health among the Nairobi urban poor. Journal of Adolescent Health 33(5): 369-377. doi:10.1016/S1054-139X(03)00213-1.

Niehaus, I. (2001). Witchcraft, power and politics: Exploring the occult in the South African Lowveld. London: Pluto Press.

Nyamukapa, C. and Gregson, S. (2005). Extended family's and women's roles in safeguarding orphans' education in AIDS-afflicted rural Zimbabwe. Social Science and Medicine 60(10): 2155-2167. doi:10.1016/j.socscimed.2004.10. 005.

Parker, E. and Short, S. (2009). Grandmother co-residence, maternal orphans, and school enrollment in sub-Saharan Africa. Journal of Family Issues 30(6): 813836. doi:10.1177/0192513X09331921.

Pedzisai, N. and Nompumelelo, N. (2016). Impact of family structure on schooling outcomes for children in South Africa. In: Makawane, M., Nduna, M., and Khalema, N. (eds.). Children in South African families: Lives and times. Newcastle Upon Tyne: Cambridge Scholars Publishing: 58-115.

Posel, D. (2001). Who are the heads of household, what do they do, and is the concept of headship useful? An analysis of headship in South Africa. Development South Africa 18(5): 651-670. doi:10.1080/03768350120097487. 
Richardson Jr, J.B. (2009). Men do matter: Ethnographic insights on the socially supportive role of the African American uncle in the lives of inner-city African American male youth. Journal of Family Issues 30(8): 1041-1069. doi:10.1177/ $0192513 X 08330930$.

Sear, R., Steele, F., McGregor, I.A., and Mace, R. (2002). The effects of kin on child mortality in rural Gambia. Demography 39(1): 43-63. doi:10.1353/dem.2002. 0010 .

Sen, A. (1990). Gender and cooperative conflicts. Tinker, I.I. (ed.). Persistent inequalities: Women and world development. Oxford: Oxford University Press: 123-149.

Shapiro, D. and Tambashe, B.O. (2001). Gender, poverty, family structure, and investments in children's education in Kinshasa, Congo. Economics of Education Review 20(4): 359-375. doi:10.1016/S0272-7757(00)00059-5.

Smith, D. (2001). Romance, parenthood, and gender in a modern African society. Ethnology 40(2): 129-151. doi:10.2307/3773927.

Spaull, N. (2013). Poverty and privilege: Primary school inequality in South Africa. International Journal of Educational Development 33(5): 436-447. doi:10.1016/j.ijedudev.2012.09.009.

Stucki, B.R. (1995). Managing the social clock: The negotiation of elderhood among rural Asante of Ghana. [PhD thesis]. Northwestern University.

Taylor, S. and Yu, D. (2009). The importance of socio-economic status in determining educational achievement in South Africa. Unpublished working paper (Economics). Stellenbosch: Stellenbosch University.

Thomas, D. (1990). Intra-household resource allocation: An inferential approach. Journal of Human Resources 25(4): 635-664. doi:10.2307/145670.

Timaeus, I. and Moultrie, T. (2008). On postponement and birth intervals. Population and Development Review 34(3): 483-510. doi:10.1111/j.1728-4457.2008.00 233.x.

Townsend, N., Madhavan, S., Tollman, S., Garenne, M., and Kahn, K. (2002). Children's residence patterns and educational attainment in rural South Africa, 1997. Population Studies 56(2): 215-225. doi:10.1080/00324720215925.

UNAIDS (2002). Report on the Global HIV/AIDS Epidemic. Geneva: UNAIDS. 
Wittenberg, M. and Collinson, M. (2007). Household transitions in rural South Africa, 1996-2003. Scandinavian Journal of Public Health 35(69 suppl.): 130-137. doi:10.1080/14034950701355429.

World Bank (2002). Education and HIV/AIDS: A window of hope. Washington, D.C.: World Bank. doi:10.1596/0-8213-5117-6.

Yamano, T., Shimamura, Y., and Sserunkuuma, D. (2006). Living arrangements and schooling of orphaned children and adolescents in Uganda. Economic Development and Cultural Change 54(4): 833-856. doi:10.1086/503586. 